\title{
O PROCESSO DE APRENDIZAGEM DA LEITURA E ESCRITA NO DECORRER DA ALFABETIZAÇÃO
}

\author{
Maria Adielma Leite da Silva ${ }^{\mathrm{I}}$
}

RESUMO: O presente projeto tem como objetivo principal falar sobre o processo de aprendizagem da leitura e escrita no decorrer da alfabetização, além de apresentar algumas reflexões sobre a psicogênese da língua escrita durante este processo, como ela vem sendo desenvolvida numa perspectiva histórica nas crianças dos anos iniciais do ensino fundamental. Inclusive, defende o acesso de todas as crianças à escola, e a importância da leitura e escrita em suas vidas. Visto que estas aquisições elas são primordiais na independência social do indivíduo nos dias atuais, suas necessidades só aumentam a cada dia. Através das pesquisas pôde-se perceber que o processo de aprendizagem da leitura e escrita é mais complexo que imaginava e que para formar leitores não basta simplesmente termos livros em casa ou na biblioteca da escola, é preciso ler para nossas crianças. Só assim elas irão pegar gosto pela leitura e possivelmente desenvolver uma boa escrita, além de um vocabulário rico.

Palavras-chaves: Leitura. Escrita. Alfabetização.

ABSTRACT: The main objective of this project is to talk about the process of learning to read and write in the course of literacy, in addition to presenting some reflections on the psychogenesis of written language during this process, as it has been developed in a historical perspective in children of the early years of elementary education. It even defends the access of all children to school, and the importance of reading and writing in their lives. Since these acquisitions are paramount in the social independence of the individual today, their needs only increase every day. Through research it was possible to realize that the process of learning to read and write is more complex than I imagined and that to train readers it is not enough to simply have books at home or in the school library, it is necessary to read for our children. Only then will they get a taste for reading and possibly develop good writing, as well as a rich vocabulary.

Keywords: Reading. Writing. Literacy.

\footnotetext{
rE-mail adielma22@gmail.com
} 


\section{INTRODUÇÃO}

E por isso, este artigo tem como objetivo principal falar sobre o processo de aprendizagem da leitura e escrita no decorrer da alfabetização, além de apresentar algumas reflexões sobre a psicogênese da língua escrita, como ela vem sendo desenvolvida numa perspectiva histórica, nas crianças das séries iniciais do ensino fundamental inclusiva defende o acesso de todas as crianças à escola, e a importância da leitura e escrita em suas vidas.

O mesmo também vem destacar a compreensão da aquisição de leitura e escrita que tem se baseado, em grande parte, nas alterações que ocorrem neste processo e as fases do desenvolvimento da escrita enfatizando a importância de seu conhecimento e de poder está identificando os níveis de escrita de cada aluno. Para que possa estar melhor aplicando metodologias em sala de aula.

\section{DESENVOLVIMENTO}

A escolha desse tema foi feita através do meu desejo de entender O Processo de Aprendizagem da Leitura e Escrita no Decorrer da Alfabetização, também com o intuito de conhecer quais os procedimentos que o educador deve levar aos alunos para ter o desejo de tal aprendizagem.

Por não ter experiência em sala de aula trabalhar com este tema foi importante, pois pôde conhecer um pouco destes processos não só na vida do aluno como na vida do professor. Com isso procuro me apropriar de metodologias que contribuam para uma docência futura.

Analises das pesquisas bibliográficas.

No ano de 1962, começam a surgir mudanças sumamente importantes a respeito da nossa maneira de compreender os processos de aquisição da língua oral da criança. De fato, acontece neste campo uma verdadeira revolução, até então dominado pelas concepções condutistas. Até esta época, a maior parte dos estudos sobre a linguagem infantil ocupava-se, predominantemente, do léxico, isto é, da quantidade e da variedade de palavras utilizadas pela criança. Essas palavras eram classificadas segundo as categorias da linguagem adulta (verbos, substantivos, adjetivos, etc.), e estudava-se como variava a proporção entre essas diferentes 
categorias de palavras, qual a relação existente entre o incremento do vocabulário, idade o sexo, o rendimento escolar etc. (FERREIRO; TEBEROSKY,20o8 P.23)

A compreensão da aquisição de leitura e escrita tem se baseado, em grande parte, nas alterações que ocorrem neste processo. Ao analisar os distúrbios da linguagem escrita, podemos traçar modelos teóricos explicativos que discriminam as diversas habilidades necessárias para que a leitura e a escrita ocorram de forma competente.

A alfabetização refere-se à aquisição da escrita enquanto aprendizagem de habilidades para leitura, escrita e as chamadas práticas de linguagem. Isso é levado a efeito, em geral, por meio do processo de escolarização e, portanto, da instrução formal. A alfabetização pertence, assim, ao âmbito do individual. O letramento, por sua vez, focaliza os aspectos sócio-históricos da aquisição da escrita. Entre outros casos, procura estudar e descrever o que ocorre nas sociedades quando adotam um sistema de escritura de maneira restrita ou generalizada; procura ainda saber quais práticas psicossociais substituem as.

A respeito do processo de ensino da leitura e da escrita, RIZZO (2005, p.14), iniciava com exercícios de domínio de todas as possíveis combinações de letras e sons, assim passavam para a etapa posterior, na qual somente depois de "os alunos já estarem manobrando bem penas e tintas na caligrafia das letras, estes eram, então, levados a formarem palavras, que, depois, reunidas, formavam frases e, finalmente, textos".

A psicogênese da língua escrita constitui-se por uma seqüência crescente de níveis de complexidade da compreensão da criança em relação à leitura e a escrita. A construção do objeto conceitual "ler e escrever", faz-se, portanto, durante vários anos, através de um processo progressivo de elaboração pessoal. Sobre a psicogênese da escrita, Weisz, (2002, p. 20) afirma que:

Segundo mostrou a psicogênese da língua escrita, em uma sociedade letrada as crianças constroem conhecimentos sobre a escrita desde muito cedo, a partir do que podem observar e das reflexões que fazem a esse respeito. Em busca de uma lógica que explique o que não compreendem quando ainda não se alfabetizaram, as crianças elaboram hipóteses muito interessantes sobre o funcionamento da escrita. (2002, p. 20)

\section{Fases do Desenvolvimento da Escrita}

GARATUJA

Nesta fase a criança começa a utilizar o papel para se expressar misturando riscos e bolinhas de forma aleatória.

PRÉ-SILÁBICA 
Nesta fase a criança aprende algumas letras, normalmente as do próprio nome, e não associa os sons das letras aos sons da língua falada, fazendo com que escreva palavras com muitas ou poucas letras. Por vezes, a criança relaciona o tamanho do objeto ao número de letras que compõem as palavras.

\section{SILÁBICA}

Nesta etapa, a criança emprega letras correspondendo a sílabas, deste modo para escrever a palavra CASA pode grafar CA, ou AZ, por exemplo. Nesta fase ainda utiliza como referência as letras do próprio nome ou dos nomes dos amigos.

\section{SILÁBICA-ALFABÉTICA}

Aqui a criança ainda confunde a sonoridade silábica com os sons de cada letra, por exemplo, para escrever CASA pode grafar CA.

\section{ALFABÉTICA}

Nesta etapa, a criança relaciona sistematicamente e de forma unívoca os sons da língua com a forma de grafar as palavras, não considerando que a escrita leva em consideração alguns princípios ortográficos regidos pela tradição etimológica da língua. Assim a criança grafa CAZA, pelo fato da letra $\mathrm{S}$ ter som de $\mathrm{Z}$ quando colocada entre duas vogais. A escrita de acordo com a norma ortográfica virá posteriormente.

Durante o processo de alfabetização, a leitura e a escrita têm sido alvo de grandes discussões por parte dos estudiosos da Educação, e graças a estes estudos que os alfabetizadores procuram cada vez mais entender este processo, cujo é de grande importância a todas as crianças e até mesmos aos adultos que estão passando por este procedimento de alfabetização.

Segundo Carvalho (2002), conforme a classe social da pessoa, as experiências com a leitura e a escrita poderão variar. Em certas famílias, a leitura e a escrita fazem parte da vida cotidiana, em outras de classe social pobre, os atos de leitura e de escrita são raros ou mesmo inexistentes, seja porque as pessoas não aprenderam a ler, seja porque suas condições de vida e de trabalho não exigem o uso da língua escrita. As motivações das pessoas são diferentes e a escola se engana quando supõe 


\begin{abstract}
que a leitura e a escrita têm o mesmo sentido para todos. Algumas pesquisas de autores contemporâneos acreditam que se a alfabetização for conduzida de forma a demonstrar que a leitura e a escrita têm função aqui e agora, e não apenas num futuro distante, incerto e imprevisível, o indivíduo poderá ter maior motivação para o esforço que a aprendizagem exige. Portanto, o trabalho de despertar o aluno para a compreensão da representação da fala através da língua escrita, serve de alicerce para o desenvolvimento de uma alfabetização significativa para os alunos.
\end{abstract}

A análise das questões sobre a leitura e a escrita está fundamentalmente ligada à concepção que se tem sobre o que é a linguagem e o que é ensinar e aprender. E essas concepções passam, obrigatoriamente, pelos objetivos que se atribuem à escola e à escolarização.

Muitas das abordagens escolares derivam de concepções de ensino e aprendizagem da palavra escrita que reduzem o processo da alfabetização e de leitura a simples decodificação dos símbolos lingüísticos. A escola transmite uma concepção de que a escrita é a transcrição da oralidade. (Cagliari, 1989: 26) Parte-se do princípio de que o aprendiz deve unicamente conhecer a estrutura da escrita, sua organização em unidades e seus princípios fundamentais, que incluiriam basicamente algumas das noções sobre a relação entre escrita e oralidade, para que possua os pré-requisitos, aprenda e desenvolva as atividades de leitura e de produção da escrita.

Mas a escrita ultrapassa sua estruturação e a relação entre o que se escreve e como se escreve demonstra a perspectiva de onde se enuncia e a intencionalidade das formas escolhidas. (Guimarães, 1995:08) A leitura, por sua vez, ultrapassa a mera decodificação porque é um processo de (re)atribuição de sentidos.

No processo de alfabetização as etapas que o aluno analfabeto irá ultrapassar para atingir o seu objetivo não diferem de um indivíduo para outro. Segundo Lemle (2003), na fase inicial de alfabetização a criança deverá desenvolver a compreensão de que os sons da ala podem ser representados graficamente; mais adiante o aluno em fase de alfabetização deverá alcançar a percepção visual fina aguçada para que consiga distinguir as letras do alfabeto conscientemente. Ainda podemos afirmar com veemência que, para que o aluno seja capaz de ler e escrever é necessário adquirir a capacidade de perceber as unidades sucessivas de sons da 
falar utilizados para enunciar as palavras e de distingui-las conscientemente uma das outras e saber isolar, na corrente da fala, as unidades que deverão ser escritas entre dois espaços brancos.

\begin{abstract}
Aprender a ler como se a leitura fosse um ato mecânico, separado da compreensão, é um desastre que acontece todos os dias. Estudar palavras soltas, sílabas isoladas, ler textos idiotas e repetir sem fim exercícios de cópia, resulta em desinteresse e rejeição em relação à escrita. (CARVALHO, 2002).
\end{abstract}

No ${ }^{\underline{a}}$ ciclo que corresponde a $\mathrm{I}^{\underline{\underline{a}}}$ e a $2^{\underline{a}}$ série na qual se dá $\mathrm{o}$ processo inicial de alfabetização e que refere-se à aquisição da escrita e da leitura, o uso do texto como unidade de ensino contribui para a formação de sujeitos letrados num processo mais amplo do aprendizado de Língua Portuguesa, pois os Parâmetros Curriculares Nacionais apontam para o uso de textos como unidade básica de ensino com o objetivo de levar o aluno a produzir e a interpretar não só textos escritos, mas também o mundo ao seu redor. Essa abordagem surgiu para substituir o antigo pensamento em que se considerava o aprendizado de língua portuguesa como uma seqüência de conteúdo em que primeiramente se ensina a junção de sílabas ou letras para formar palavras e a sua junção para formar frases e posteriormente juntar frases para formar textos. A essa abordagem os Parâmetros nomeiam como aditiva:

Essa abordagem aditiva levou a escola a trabalhar com "textos" que só servem para ensinar a ler. "Textos" que não existem fora da escola e, como os escritos das cartilhas, em geral, nem sequer podem ser considerados textos, pois não passam de simples agregados de frases. (BRASIL, 1997, p. 35)

Levar ao alcance dos alunos diferentes portadores de texto, pode ser uma forma de incentivar a leitura e a escrita na fase de alfabetização. Cartas, listas, histórias, poesias, bilhetes, etc, poderão mostrar aos alunos a amplitude do mundo letrado e despertará a curiosidade para explorar cada vez mais este mundo.

O trabalho com contas de água, luz e telefone, dinheiro (notas e moedas) e cheques ou documentos pessoais como carteira de trabalho, de identidade, título de eleitor também é um ótimo suporte para que o aluno saiba a utilidade da escrita e da leitura, pois são 
instrumentos utilizados no dia a dia das pessoas próximas e nas brincadeiras de faz-de-conta das próprias crianças.

Outro aspecto importante a ser trabalhado é a distinção entre letras e números. Algumas crianças tendem a confundir letras e números, fazendo uso de algarismos, na escrita das palavras, como se fossem letras. Para ajudar aos alunos a ultrapassarem esta dificuldade natural no processo de alfabetização, o professor deverá trabalhar as diferenças entre números e letras em diferentes contextos.

\section{CONSIDERAÇÕES FINAIS}

Diante do que foi exposto acima. Conclui-se que é através da leitura e escrita que o homem é inserido neste mundo qual está sendo formado, além do que, o ato de ler e escrever torna o ser humano um sujeito mais independente na sociedade em que vivemos.

\section{REFERÊNCIA}

http://www.scielo.br/scielo.php?pid=Soro1733020020081000o8\&script=sci_arttext\&tlng=es: acesso em i7 de outubro de 2010

http://www.smec.salvador.ba.gov.br/site/documentos/espaco-virtual/espaco-jornadapedagogica/lingua-portuguesa/proC3\%Articas-de-leitura-e-escrita-na-alfabetizacao.pdf acesso em i9 de outubro de 2010

http://wwwio.unopar.br/unopar/ava/aluno/formwebaula.action?gecronofer.gcofCd $=5899$ $2 \&$ gecroncont.gcrcNrPagina $=5 \&$ geoferturm. goftCd $=1052888 \&$ gediscofer . 0 ofdCd $=180746$ : acesso em 27 de outubro de 2010 http://www.espacoacademico.com.br/o42/42pc_amaral.htm: acesso em or de novembro de 2010

http://www.webartigos.com/articles/3046/r/A-Importancia-Da-Leitura-Nas-SeriesIniciais/paginar.html : acesso em 02 de novembro de 2010

http://biblioteca.claretiano.edu.br/phl8/pdf/200or498.pdf acessado em o6 de novembro de 2010 